СТАТЬИ

УДК 630:632.7.04.08

РОБИНИЕВАЯ КРАЕВАЯ ГАЛЛИЦА (OBOLODIPLOSIS ROBINIAE НАLDEMAN) В ЗАЩИТНЫХ НАСАЖДЕНИЯХ НИЖНЕГО ПОВОЛЖЬЯ

\author{
Белицкая М.Н., Грибуст И.Р., Блюм К.Я.
}

ФГБНУ «Федеральный научный центр агроэкологии, комплексных мелиоращчй и зашитного лесоразведения Российской академии наук», Волгоград, е-mail: cheizer9@yandex.ru

C 2007-2008 гг. в кронах древесных растений родового комплекса Robinia, произрастающих в насаждениях в засушливых условиях Нижнего Поволжья, фиксируются инвазивные насекомые филлофаги. Среди выявленных инвайдеров полностью адаптировалась к условиям региона и расселилась повсеместно в различных насаждениях робиниевая краевая, или белоакациевая, листовая галлица Obolodiplosis robiniae Halde-man, 1847 (Diptera, Cecidomyiidae). Представлены современные данные по особенностям заселения краевой галлицей Obolodiplosis robiniae Haldeman деревьев Robinia spp. Приведены результаты наблюдений и учетов за период 2016-2019 гг. Целью настоящих исследований являлись детальное изучение и анализ биотопического распределения O. robiniae в защитных насаждениях разных типов и экологических категорий. Установлено, что робиниевая галлица заселяет разные виды древесных растений родового комплекса Robinia: R. pseudoacacia, R. viscosa и R. neomexicana. На территории Волгоградской области в большинстве биотопов инвайдер заселяет R. viscosa и R. neomexicacana. При этом заселенность R. pseudoacacia галлицей достигает $100 \%$. Выявлено влияние возраста деревьев, категории насаждений, уровня антропогенного воздействия на встречаемость O. robiniae. Обнаружено, что заселенность приспевающих и перестойных деревьев робинии краевой галлицей на 60-70\% выше по сравнению с молодыми растениями. По результатам наблюдений показано, что повышение уровня техногенного загрязнения приводит к значительному увеличению (на 56-99\%) заселенности Robinia spp. вредителем O. robiniae. Установлена вариабельность плотности галлов галлицы в зависимости от категории насаждений. Выявленные особенности численности, заселения древесных видов и распространения O. robiniae в разных насаждениях обусловливают относительную стабильность популяции рассматриваемого вида в условиях региона. На сегодняшний день О. robiniae укрепилась в насаждениях Нижнего Поволжья. На территории вторичного ареала филлофаг расширяет спектр трофических предпочтений, при этом локальные очаги вредителя приурочены к загущенным посадкам с преобладанием R. pseudoacacia.

Ключевые слова: инвазивный вид, Obolodiplosis robiniae, защитные насаждения, экологические особенности, древесные растения родового комплекса Robinia L., заселенность, распространение, галлы

\title{
LOCUST GALL MIDGE (OBOLODIPLOSIS ROBINIAE HALDEMAN) IN THE PROTECTIVE PLANTINGS OF THE LOWER VOLGA
}

\section{Belitskaya M.N., Gribust I.R., Blyum K.Ya.}

Federal State Budget Scientific Institution «Federal Scientific Centre of Agroecology,

Complex Melioration and Protective Afforestation of the Russian Academy of Sciences», Volgograd,e-mail: cheizer9@yandex.ru

In the arid conditions of the Lower Volga region since 2007-2008, in the crowns of woody plants of the Robinia genus complex are recorded growing the invasive insect phyllophages in the protective forest plantings. Among the identified insiders fully adapted to the conditions of the region and settled everywhere in various plantings phyllophage of the robinia (white acacia) locust gall midge Obolodiplosis robiniae Haldeman, 1847 (Diptera, Cecidomyiidae). Presents recent data on the specifics of the settlement of the population locust gall midge Obolodiplosis robiniae Haldeman trees Robinia spp. The results of observations and surveys for the period 2016-2019 are presented. The purpose of this study was to study and analyze in detail the biotopic distribution of O. robiniae in protective stands of different types and ecological categories. It has been established that the locust gall midge populates different species of woody plants of the generic Robinia complex, growing in the territory of this zone: R. pseudoacacia, R. viscosa, and R. neomexicana. On the territory of the Volgograd region, in most biotopes, the invader inhabits R. viscosa and $\mathrm{R}$. neomexicacana. At the same time, the population locusr gall midge of R. pseudoacacia with reaches $100 \%$. The influence of the age of trees, the category of plantations, and the level of anthropogenic impact on the occurrence of O. robiniae was revealed. It was found that the population of the ripening and overripe Robinia trees by the locust gall midge is $60-70 \%$ higher in comparison with young plants. According to the results of observations, it is shown that an increase in the level of technogenic pollution leads to a significant increase (by 56-99\%) in the population of Robinia spp. the pest of O. robiniae. The variability of the density of galls of locust gall midges depending on the category of stands was established. The revealed features of the abundance, population of tree species, and the distribution of $\mathrm{O}$. robiniae in different plantings determine the relative stability of the population of the species in question in the region. To date, O. robiniae has been strengthened in the protective plantings of the Lower Volga region. On the site secondary areal at this phillophag expands the range of trophic preferences, at the same time local foci of the pest are confined to thickened plantings with a predominance of R. pseudoacacia.

Keywords: invasive species, Obolodiplosis robiniae, protective plantings, ecological features, woody plants of the Robinia L. family complex, population, distribution, galls

Одним из основных элементов оптимизации территорий с низкой лесистостью в засушливых регионах становится лесная мелиорация, предусматривающая создание систем полифункциональных защитных насаждений различных типов и категорий, 
в состав которых входят хозяйственно ценные виды древесных растений [1]. Важное практическое значение при расширении ассортимента, повышении хозяйственной эффективности насаждений, их декоративности и долговечности имеют деревья и кустарники родового комплекса Robinia L., 1753 [1], естественным ареалом которых является Северная Америка.

Начало интродукции древесных растений рода Robinia в России приходится на конец XVIII - начало XIX вв., популяризация их в посадках начинается с середины XX в. [1]. Устойчивость к неблагоприятным факторам окружающей среды (засухе, заморозкам и др.) и отсутствие необходимости в особом агротехническом уходе определили широкое применение Robinia spp. в озеленении населенных пунктов и при создании лесополос разных конструктивных параметров и целевого назначения [1]. До недавнего времени Robinia spp. в границах своего вторичного ареала характеризовалась отсутствием специализированных видов филлофагов [2]. Однако начало XXI в. ознаменовалось пополнением состава населения насекомых чужеземными видами, проникающими сюда на фоне интенсивного развития торгово-экономических связей [3-5].

Среди выявленных инвазивных насекомых наиболее распространена и многочисленна в кронах Robinia spp. робиниевая краевая, или белоакациевая, листовая галлица Obolodiplosis robiniae Haldeman, 1847 (Diptera, Cecidomyiidae) [2, 5]. Повреждение галлицей ассимиляционного аппарата деревьев со временем грозит перерасти в серьезную проблему для насаждений Нижнего Поволжья. В связи с этим детальное изучение распространения O. robiniae, особенностей заселения ею листвы, выявление ее биотопических предпочтений с учетом экологических условий посадок приобретают особую актуальность и обусловливают необходимость своевременного контроля жизнедеятельности вредителя в регионе.

Цель исследований: детальное изучение и анализ биотопического распределения O. robiniae Haldeman. в защитных насаждениях разных типов и экологических категорий Нижневолжского региона.

\section{Материалы и методы исследования}

В основу настоящей работы положены результаты учетов и наблюдений, выполненных в вегетационные периоды
2016-2019 гг. Исследование биотопической приуроченности галлицы выполняли в защитных насаждениях ФНЦ агроэкологии РАН и в рекреационно-озеленительных посадках разных категориях с участием древесных видов Robinia spp.

Сбор материала осуществлялся также в насаждениях Ольховского, Камышинского, Дубовского и Октябрьского районов Волгоградской области (рис. 1). Пробные площадки в насаждениях закладывались с учетом видового состава робинии и стадии жизненного цикла растения. Возраст деревьев устанавливался с использованием бурава Пресслера.

Выявление данного филлофага в кронах робинии осуществлялось с применением общепринятых методов обследования насаждений, в том числе предложенных Ю.И. Гниненко и М. Главендекич $[2,3,6]$. В ходе визуального обследования особенно тщательно осматривалась листва на ветвях нижней и средней частей кроны. Встречаемость O. robiniae определялась как процентное соотношение заселенных ею деревьев к общему количеству обследованных растений. При учете численности робиниевой краевой галлицы из крон модельных деревьев отбирались ветви, на которых подсчитывались количество сложных листьев и число простых листочков на каждом сложном. Затем согласно методике Ю.И. Гниненко [4] подсчитывали долю заселенных листьев, плотность галлов на листовой пластинке, число личинок в каждом галле. Всего были обследованы 2250 деревьев, 735 сложных и 11025 простых листочков.

\section{Результаты исследования и их обсуждение}

В насаждениях Волгоградской области встречаются следующие виды робинии: псевдоакация, или белая акация (Robinia pseudoacacia L.), новомексиканская ( $R$. пеоmexicacana A. Grey.) и клейкая (R. viscosa Vent.). Среди них наиболее широко распространен первый вид [1].

R. pseudoacacia (Linnaeus, 1753) - быстрорастущее листопадное дерево высотой 20-25 м (порой до 30-35 м), с ажурной, раскидистой кроной из нескольких ярусов ветвей и глубокой корневой системой. На корнях наличествуют клубеньки с азотофиксирующими бактериями. Ствол имеет толстую трещиноватую кору. Листья очередные непарноперистосложные, состоящие из 7-19 гладких светло-зеленого цвета маленьких листочков округлой формы. 


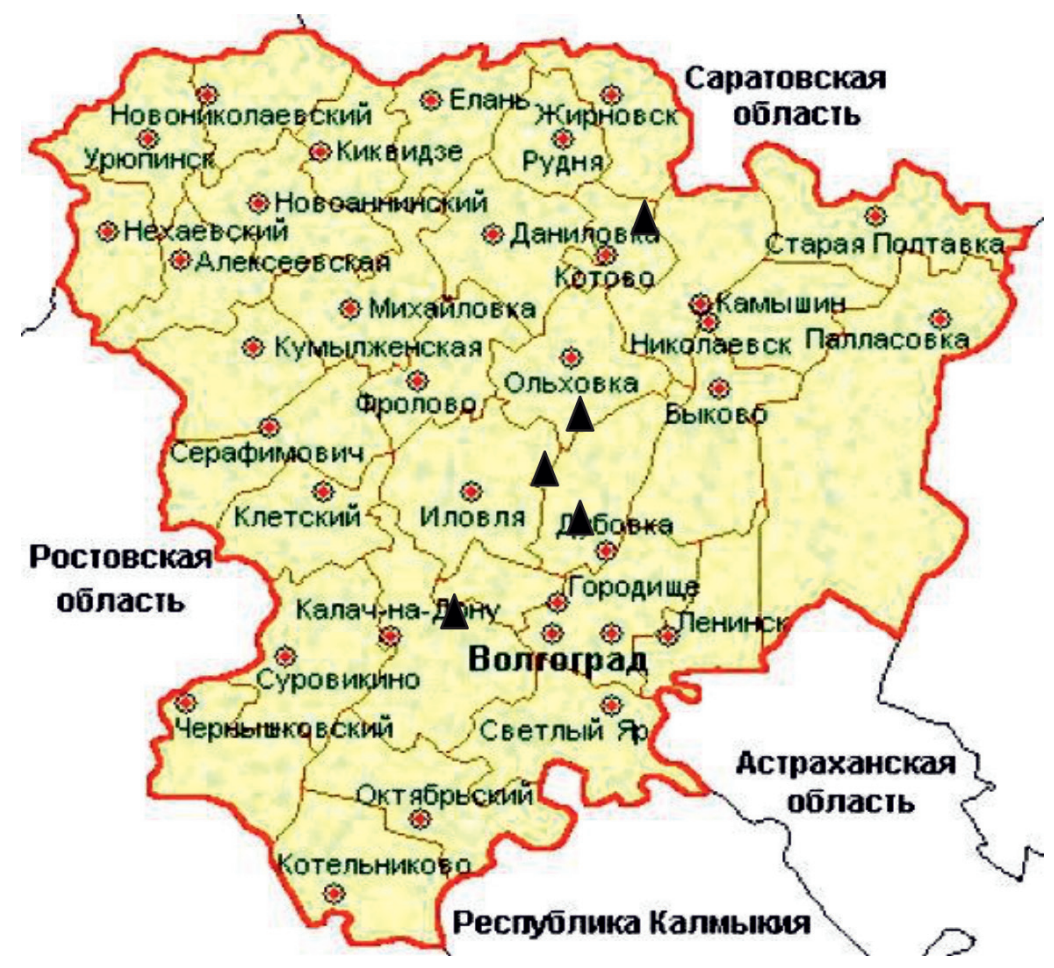

Рис. 1. Стационары и точки сбора фактического материала на территории Волгоградской области

Заселенность разных видов робинии Obolodiplosis robiniae

Таблица 1

\begin{tabular}{|l|c|c|c|c|}
\hline \multirow{2}{*}{\begin{tabular}{c}
\multirow{2}{*}{$\begin{array}{c}\text { Виды } \\
\text { Robinia }\end{array}$} \\
\cline { 2 - 3 } R. pseudoacacia
\end{tabular}} & \multicolumn{2}{|c|}{ Кол-во обследованных деревьев } & $\begin{array}{c}\text { Доля простых ли- } \\
\text { стьев с галлами, \% }\end{array}$ & $\begin{array}{c}\text { Плотность галлов, } \\
\text { шт./лист }\end{array}$ \\
\hline R. neomexicacana & 658 & 84,4 & $59,9 \pm 3,1$ & $1,7 \pm 0,10$ \\
\hline R. viscosa & 423 & 47,9 & $31,5 \pm 2,4$ & $1,12 \pm 0,05$ \\
\hline
\end{tabular}

O. robiniae Haldeman., проникшая в Европу из Северной Америки в первые годы XXI в. [3, 7], на территории России впервые была обнаружена в 2005 г. на юге Приморского края [3].

Вторжение данного инвазивного вида в экосистемы Нижнего Поволжья произошло несколькими годами позже - в 20072008 гг. [2, 3]. При проведении полевых работ в 2009 г. галлица была зафиксирована нами в отдельных категориях рекреационно-озеленительных насаждений Волгограда. К 2016 г. филлофаг полностью адаптировался к условиям региона и расселился повсеместно в защитных насаждениях различного целевого назначения.

Согласно литературным данным $O$. robiniae - монофаг, развивается исключительно на листьях $R$. pseudoacacia и $R$. viscosa [3].
Однако на территории Волгоградской области в большинстве исследованных нами биоценозов инвайдер заселяет $R$. viscosa и $R$. neomexicacana. При этом заселенность $R$. pseudoacacia галлицей может достигать $100 \%$ (табл. 1).

Факторы, влияющие на заселенность деревьев O. robiniae в условиях Нижнего Поволжья, ее пространственное распределение и численность, практически не изучены. Однако знание их необходимо, поскольку это позволит в лучшей степени понять механизмы, которые инициируют, регулируют распространение филлофага и роль антропогенных факторов в этом процессе.

При анализе изменений пространственного распространения вредителя выявлено, что экологической основой данного показателя является соотношение с параметрами 
окружающей среды. К числу важнейших факторов относятся: возраст деревьев, категория насаждений и уровень техногенного воздействия.

Установлено, что с увеличением возраста растений происходит существенный рост заселенности деревьев $O$. robiniae $u$ количества освоенных ею листьев. К концу первого года жизни, как правило, до 0,6\% сеянцев бывают повреждены данным филлофагом. По мере увеличения возраста растений и смыкания крон, сопровождающихся значительным изменением микроклимата (температуры, влажности, уровня инсоляции), санитарного состояния, неизбежно происходит увеличение числа заселенных галлицей деревьев на 32,6\% в приспевающих и на 49,2\% в перестойных насаждениях (табл. 2). Одновременно наблюдается повышение доли освоенных вредителем простых листочков в кроне на 39,4\% и 58,1\% соответственно. Более высокой плотностью галлов отличаются молодые листочки, расположенные на верхушках побегов.

На обследованной территории робиниевая краевая галлица демонстрирует постоянную встречаемость на $R$. pseudoacacia, культивируемой в разных типах и категориях лесных полос и рекреационно-озеленительных насаждений. При этом встречаемость вида в этих посадках сильно варьирует (рис. 2).

Заселенность деревьев вредителем зависит от особенностей экологических условий местообитаний. Многолетние наблюдения показали, что максимальное количество заселенных галлицей деревьев (97,9-100\%) ежегодно отмечается в биотопах с высоким уровнем техногенного пресса (придорожных лесных полосах, скверах). Аналогичную ситуацию отмечают исследователи в Румынии $[7,8]$. Довольно велика доля освоенных филлофагом деревьев во внутриквартальных посадках («закрытых территориях») - 78,2\%. Снижение техногенного загрязнения окружающей среды, несмотря на существенную степень рекреационного пресса, сопровождается значительным уменьшением числа заселенных деревьев (на 56,0-99,0\%). Наиболее ярко это выражено в парках и полезащитных лесополосах. В данном случае важнейшими причинами различий являются также широкий породный состав древесных растений, низкая представленность $R$. pseudoacacia и ее молодой возраст (8-10 лет).

Таблица 2

Особенности изменения заселенности деревьев и обилия простых листочков с галлами $O$. robiniae в насаждениях разного возраста

\begin{tabular}{|l|c|c|c|}
\hline \multicolumn{1}{|c|}{$\begin{array}{c}\text { Возрастные } \\
\text { стадии деревьев }\end{array}$} & $\begin{array}{c}\text { Количество обследо- } \\
\text { ванных деревьев, шт. }\end{array}$ & $\begin{array}{c}\text { В том числе заселено } \\
\text { галлицей, \% }\end{array}$ & $\begin{array}{c}\text { Доля простых листоч- } \\
\text { ков с галлами, \% }\end{array}$ \\
\hline Молодые (до 10 лет) & 126 & $29,3 \pm 0,67$ & $10,2 \pm 0,33$ \\
\hline После смыкания крон (11-20 лет) & 188 & $50,8 \pm 1,05$ & $31,5 \pm 0,75$ \\
\hline Приспевающие (31-40 лет) & 211 & $90,4 \pm 1,47$ & $83,9 \pm 1,53$ \\
\hline Перестойные (старше 50 лет) & 139 & $100,0 \pm 3,11$ & $89,6 \pm 2,82$ \\
\hline
\end{tabular}

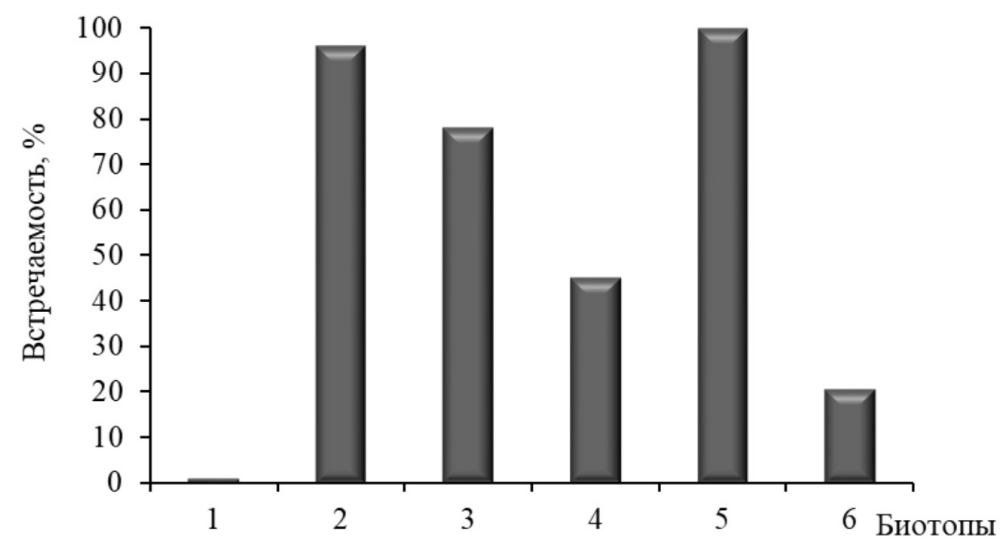

Puc. 2. Bстречаемость Obolodiplosis robiniae деревьев в насаждениях разных категорий:

1 - парки; 2 - скверы; 3 - внутриквартальные посадки; 4 - дендрологические коллекиии; 5 - придорожные лесополосы; 6- полезащитные лесополосы 
Таблица 3

Биотопическое распределение обилия простых листочков с галлами

\begin{tabular}{|l|c|c|c|c|}
\hline \multicolumn{1}{|c|}{$\begin{array}{c}\text { Категория } \\
\text { насаждения }\end{array}$} & $\begin{array}{c}\text { Санитарное } \\
\text { состояние, } \\
\text { балл }\end{array}$ & $\begin{array}{c}\text { Проанализировано } \\
\text { сложных } \\
\text { листьев, шт. }\end{array}$ & $\begin{array}{c}\text { Число простых } \\
\text { листочков, } \\
\text { шт.сложный лист }\end{array}$ & $\begin{array}{c}\text { Кол-во простых } \\
\text { листьв с галлами, } \\
\%\end{array}$ \\
\hline $\begin{array}{l}\text { Дендрологические } \\
\text { коллекции }\end{array}$ & 1,08 & 36 & $16,07 \pm 1,05$ & $4,90 \pm 0,12$ \\
\hline Парки & 1,44 & 61 & $14,87 \pm 1,10$ & $0,04 \pm 0,003$ \\
\hline Скверы & 2,06 & 39 & $14,93 \pm 0,96$ & $51,98 \pm 2,32$ \\
\hline $\begin{array}{l}\text { Внутриквартальные } \\
\text { посадки }\end{array}$ & 2,94 & 48 & $13,67 \pm 0,68$ & $29,85 \pm 1,30$ \\
\hline $\begin{array}{l}\text { Придорожные } \\
\text { лесополосы }\end{array}$ & 3,52 & 41 & $13,27 \pm 0,72$ & $75,21 \pm 2,09$ \\
\hline $\begin{array}{l}\text { Полезащитные } \\
\text { лесополосы }\end{array}$ & 1,95 & $13,55 \pm 0,89$ & $33,21 \pm 2,86$ \\
\hline
\end{tabular}

Придорожные лесные полосы, расположенные по периметру городов, отличаются максимально плотной заселенностью листвы O. robiniea. По всей вероятности, это связано не только с загрязнением выхлопными газами автотранспорта, в том числе автомобилей повышенной грузоподъемности, но и с низким разнообразием дендрофлоры в этих насаждениях, в первую очередь с загущенностью посадок, особенностями их конструктивных параметров и микроклимата.

Подобным образом изменяется обилие заселенных вредителем простых листочков в городских посадках. Максимальное количество листочков с галлами выявлено в насаждениях, подверженных интенсивному загрязнению атмосферного воздуха выхлопными газами автотранспорта и отличающихся ослабленностью: средний балл общего состояния варьирует в пределах 2,06-3,52 (табл. 3).

Уменьшение техногенного пресса сопровождается снижением освоенных галлицей листочков на 45,36-75,17\%. Минимальное число поврежденных листьев зафиксировано в кронах деревьев парков, для которых характерны широкий ассортимент древесной растительности и незначительное участие в их составе $R$. pseudoacacia, в том числе молодых (8-10 лет) деревьев.

В процессе питания личинки $O$. robiniae формируют галлы, представляющие собой загнутые вниз утолщения листовой пластинки более бледного цвета. Длина их колеблется от 7 до 15 мм (рис. 3). Галлы располагаются по всему краю листа на разном расстоянии от черешка.

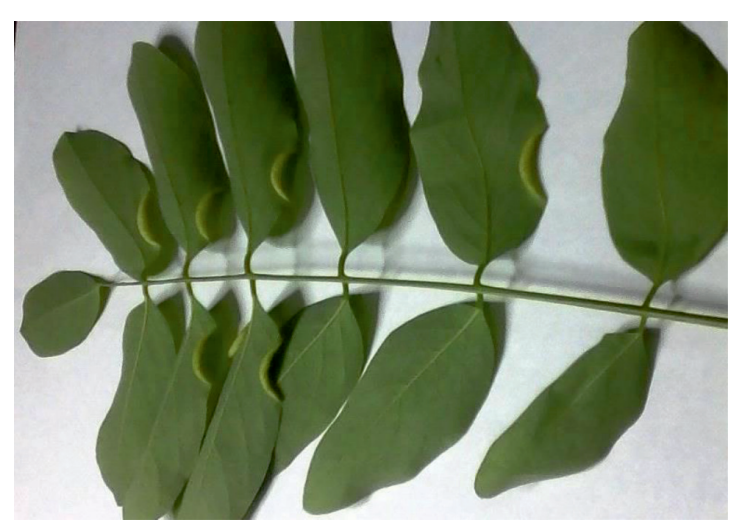

Рис. 3. Повреждения листьев робинии Obolodiplosis robiniae

Количество галлов на простых листочках варьирует от 1 до 7 экземпляров (табл. 4). При этом в рекреационно-озеленительных насаждениях на большинстве листьев $\quad(77,5-100 \%)$ насчитывается от 1 до 3 галлов. Иная ситуация зафиксирована в защитных лесных насаждениях, преимущественно в придорожных лесополосах. Здесь на 69,5\% простых листочков чаще встречается по 4-7 галлов.

При вскрытии галлов не обнаружено ярко выраженной зависимости количественного обилия личинок в них от числа галлов на простом листочке (табл. 5). Анализ полученных данных показал, что в ряде галлов (8,8\% от общего количества) личинки отсутствуют. Причина этого явления в данное время пока не установлена. 
Таблица 4

Соотношение заселенных $O$. robiniae простых листочков с разным числом галлов

\begin{tabular}{|c|c|c|c|c|c|c|c|c|}
\hline \multirow{2}{*}{$\begin{array}{c}\text { Категория } \\
\text { насаждений }\end{array}$} & \multirow{2}{*}{$\begin{array}{c}\text { Проанализировано } \\
\text { листьев, шт. }\end{array}$} & \multicolumn{7}{|c|}{ Доля листьев с числом галлов, \% } \\
\hline & & 1 & 2 & 3 & 4 & 5 & 6 & 7 \\
\hline $\begin{array}{l}\text { Дендрологическая } \\
\text { коллекция }\end{array}$ & 2108 & 27,78 & 22,22 & 50,0 & - & - & - & - \\
\hline Парк & 157 & 97,9 & 5,10 & - & - & - & - & - \\
\hline Сквер & 115 & 26,96 & 29,57 & 20,86 & 13,91 & 8,70 & - & - \\
\hline $\begin{array}{l}\text { Внутриквартальные } \\
\text { посадки }\end{array}$ & 255 & 23,64 & 29,08 & 32,73 & 14,55 & - & - & - \\
\hline $\begin{array}{l}\text { Полезащитные } \\
\text { лесополосы }\end{array}$ & 173 & 12,97 & 17,81 & 25,44 & 23,41 & 13,25 & 7,12 & - \\
\hline $\begin{array}{l}\text { Придорожные } \\
\text { лесополосы }\end{array}$ & 181 & 8,64 & 9,75 & 11,10 & 14,83 & 16,17 & 22,22 & 17,29 \\
\hline
\end{tabular}

Таблица 5

Плотность личинок O. robiniea в галле при разном числе галлов на простом листе

\begin{tabular}{|c|c|c|c|c|}
\hline \multirow{2}{*}{$\begin{array}{c}\text { Среднее число простых листьев } \\
\text { на } 1 \text { сложный, шт. }\end{array}$} & \multicolumn{2}{|c|}{ В том числе листьев с галлами } & \multirow{2}{*}{$\begin{array}{c}\text { Кол-во галлов, } \\
\text { шт./лист }\end{array}$} & \multirow{2}{*}{$\begin{array}{l}\text { Число личинок } \\
\text { в галле, шт. }\end{array}$} \\
\hline & шт. & $\%$ & & \\
\hline \multirow{7}{*}{17,8} & \multirow{7}{*}{10,09} & \multirow{7}{*}{61,9} & 1 & $1,71 \pm 0,67$ \\
\hline & & & 2 & $1,79 \pm 0,81$ \\
\hline & & & 3 & $1,68 \pm 0,69$ \\
\hline & & & 4 & $1,66 \pm 0,51$ \\
\hline & & & 5 & $1,65 \pm 0,48$ \\
\hline & & & 6 & $1,68 \pm 0,53$ \\
\hline & & & 7 & $1,66 \pm 0,49$ \\
\hline
\end{tabular}

Плотность галлов $O$. robiniea в насаждениях разных типов сильно варьирует. Более высоким значением данного показателя отличаются лесные полосы (полезащитные, придорожные). Среди озеленительных насаждений робиниевая краевая галлица предпочитает осваивать $R$. pseudoacacia в скверах и внутриквартальных посадках, подвергающихся более высокому рекреационному и техногенному воздействию. В ходе исследований не выявлено скольколибо заметного изменения числа личинок в галле в зависимости от их количественного обилия на листочке.

\section{Заключение}

В настоящее время O. robiniae имеет широкое распространение на территории вторичного ареала. Основные тенденции в распространении и заселенности робинии галлицей в сухостепных условиях Нижнего Поволжья обусловлены прежде всего спецификой насаждений (видовым составом и возрастом деревьев рода робиния, категорией насаждений, уровнем антропогенного воздействия и др.). Наиболее предпочтительным кормовым растением для робиниевой краевой галлицы является $R$. pseudoacacia, причем с увеличением возраста деревьев их заселенность и плотность филлофага увеличиваются. Локальные очаги вида приурочены к загущенным придорожным лесополосам с преобладанием $R$. pseudoacacia, подверженным интенсивному воздействию выхлопных газов автотранспорта.

Исследования выполнены в рамках Государственного задания № 0713-20190004 ФНЦ агроэкологии РАН в градиенте региональных изменений на Приволжской возвышенности.

\section{Список литературы / References}

1. Семенютина А.В., Лазарев. С.Е. Диагностические признаки представителей рода Robinia L. по генеративным показателям в интродукционных популяциях // World Ecology Journal. 2019. Т. 9. № 2. P. 64-94. DOI: 10.25726/ NM.2019.85.96.003.

Semenyutina A.V., Lazarev. S.E. Diagnostic characters of representatives of the genus Robinia L. according to generative indicators in introduction populations // World Ecology Journal. 2019. Vol. 9. № 2. P. 64-94 (in Russian).

2. Белицкая М.Н., Грибуст И.Р., Блюм К.Я. Инвазивные вредители древесных растений сем. Fabaceae в насаждениях Нижневолжского региона // Научно агрономический журнал. 2019. № 3. C. 19-23. DOI: 10.34736/FNC.2019.106.3.006. 
Belitskaya M.N., Gribust I.R., Blum K.Ya. Invasive pests of woody plants Fabaceae in the stands of the Lower Volga region // Nauchno agronomicheskiy zhurnal. 2019. № 3. P. 19 23 (in Russian).

3. Гниненко Ю.И., Главендекич М. Рекомендации по выявлению белоакациевой листовой галлицы Obolodip losis robinea (Haldeman) (Diptera, Cecidomyiidae). ПушкиноБелград: ВПРС МОБЗР, 2010. 25 c.

Gninenko Yu.I., Glavendekich M. Recommendations for the identification of the white acacia leaf gall midge Obolodiplosis robinea (Haldeman) (Diptera, Cecidomyiidae). PushkinoBelgrade: VPRS MOBZR, 2010. 25 p. (in Russian).

4. Гниненко Ю.И. Белоакациевая листовая галлица Obolodiplosis robiniea (Hald., 1847) (Diptera, Cecidomyiidae) первая находка на Сахалине // Евроазиатский энтомологический журнал. 2013. Т. 12. № 6. С. 551-552.

Gninenko Yu.I. The first record of Obolodiplosis robiniea (Hald., 1847) (Diptera, Cecidomyiidae) from Sakhalin, Russia // Yevroaziatskiy entomologicheskiy zhurnal. 2013. Vol. 12. № 6. P. 551-552 (in Russian).

5. Мартынов В.В., Никулина Т.В., Левченко И.С. Инвазивные вредители робинии ложноакациевой (Robinia pseudoacacia L., 1753) в степной зоне Восточного Причерноморья // X Чтения памяти О.А. Катаева: тезисы докладов конференции. СПб., 2018. С. 72.

Martynov V.V., Nikulina T.V., Levchenko I.S. Invasive pests of pseudoacacia L. Robinia pseudoacacia L., 1753 in the steppe zone of the Eastern Black Sea // X Chteniya pamyati O.A. Katayeva: tezisy dokladov konferentsii. SPb., 2018. P. 72 (in Russian).

6. Наставление по организации, и ведению лесопатологического мониторинга в лесах России / Сост. А.Д. Маслов Е.Г. Мозолевская, Н.А. Лисов и др. М.: ВНИИЛМ, 2001. 86 с.

Manual on the organization and conduct of forest pathological monitoring in the forests of Russia // Sost. A.D. Maslov, E.G. Mozolevskaya, H.A. Lisov i dr. M.: VNIIILM, 2001. 86 p. (in Russian).

7. Bálint J., Neacssu P., Adalbert B., Fail J., Vétek G. First record of the black locust gall midge, Obolodiplosis robiniae (Haldeman) (Diptera: Cecidomyiidae), in Romania. North-Western Journal of Zoology. 2010. Vol. 6 (2). P. 319-322.

8. Bakay L., Kollár J. Influence of urban environment on the population biology of alien insect species: Obolodiplosis robiniae (Haldeman, 1847), Parectopa robiniella Clemens,
1863 and Phyllonorycter robiniella Clemens, 1859 in conditions of Slovakia. Pensee Journal. 2014. Vol. 76. No. 6. P. 88-94.

9. Белицкая М.Н. Особенности комплекса филлофагов древесных растений семейства бобовые (Fabaceae Lindl.) в защитных насаждениях Волгограда // X Чтения памяти О.А. Катаева: тезисы докладов конференции. СПб., 2018. C. 11 .

Belitskaya M.N. Features of the complex of phyllophages of woody plants of the legume family (Fabaceae Lindl.) In the protective stands of Volgograd // X Chteniya pamyati O.A. Katayeva: tezisy dokladov konferentsii. SPb., 2018. P. 11 (in Russian).

10. Есипенко Л.П. Биологические инвазии как глобальная экологическая проблема юга России // Юг России: экология, развитие. 2012. Т. 7. № 4. С. 21-25.

Esipenko L.P. Biological invasions as a global environmental problem in the south of Russia // Yug Rossii: ekologiya, razvitiye. 2012. Vol. 7. № 4. P. 21-25 (in Russian).

11. Мозолевская Е.Г., Куликова Е.Г. Экологические категории городских насаждений. Экология, мониторинг и рациональное природопользование // Научные труды МГУЛ. 2000. № 302-1. C. 5-12.

Mozolevskaya EG, Kulikova EG Ecological categories of urban plantations. Ecology, monitoring and environmental management // Nauchnyye trudy MGUL. 2000. № 302-1. P. 5-12 (in Russian).

12. Синчук О.В., Рогинский А.С., Буга С.В. Первая находка Obolodiplosis robiniae (Haldeman, 1847) (Diptera: Cecidomyiidae) на территории Брянской области // Евроазиатский энтомологический журнал. 2018. T. 17. № 6. С. 401-402.

Sinchuk O.V., Roginsky A.S., Buga S.V. The first find of Obolodiplosis robiniae (Haldeman, 1847) (Diptera: Cecidomyiidae) in the Bryansk region // Yevroaziatskiy entomologicheskiy zhurnal. 2018. Vol. 17. № 6. P. 401-402 (in Russian).

13. Стручаев В.В. Инвазионные членистоногие филлофаги деревьев Белгородской области // Научные ведомости БелГУ. Серия Естественные науки. 2013. № 3 (146). C. $50-54$.

Struchaev V.V. Invasive arthropod phylophages of trees of the Belgorod region // Nauchnyye vedomosti BelGU. Seriya Yestestvennyye nauki. 2013. № 3 (146). P. 50-54 (in Russian).

14. Kostro-Ambroziak A., Mieczkowska A. The first record of the black locust gall midge Obolodiplosis robiniae (Haldeman, 1847) (Diptera: Cecidomyiidae) from northeastern Poland. Wiadomości entomologiczne. 2017. Vol. 36 (2). P. 126-127. 